\title{
The synergistic effect of catalysts on hydrogen desorption properties of $\mathrm{MgH}_{2}-\mathrm{TiO}_{2}-\mathrm{NiO}$ nanocomposite
}

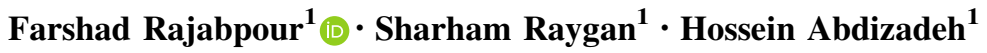

Received: 1 August 2016/Accepted: 19 October 2016/Published online: 26 October 2016

(C) The Author(s) 2016. This article is published with open access at Springerlink.com

\begin{abstract}
The high desorption temperature and slow desorption kinetics of $\mathrm{MgH}_{2}$ makes it less competitive for future mobile applications; using a catalyst accompanied by mechanical milling seems to be a good solution to overcome those problems. Therefore, the addition of $\mathrm{TiO}_{2}$ and $\mathrm{NiO}$ to $\mathrm{MgH}_{2}$ accompanied by $15 \mathrm{~h}$ of mechanical milling was considered in this study. The phase constituent and hydrogen desorption of the powder mixture were investigated using X-ray diffraction (XRD) and a Sieverttype apparatus, respectively. XRD results showed that after milling, no binary or ternary compounds were formed, but hydrogen desorption time decreased and the desorbed hydrogen content increased. It seems that the increase in desorbed hydrogen was related to the simultaneous catalytic effect of $\mathrm{TiO}_{2}$ and $\mathrm{NiO}$ as well as mechanical milling. The results showed that the addition of both catalysts can improve the hydrogen desorption behavior of $\mathrm{MgH}_{2^{-}}$ based nanocomposite compared to the addition of only one catalyst of the same amount.
\end{abstract}

Keywords $\mathrm{MgH}_{2} \cdot$ Hydrogen desorption $\cdot \mathrm{NiO} \cdot \mathrm{TiO}_{2}$. Synergism

Farshad Rajabpour

frajabpoor@gmail.com

1 School of Metallurgy and Materials Engineering, College of Engineering, University of Tehran, Tehran, Iran

\section{Introduction}

Nowadays, it is a known fact that fossil fuels cause a series of ecological problems. Hydrogen is a viable energy resource alternative to conventional fossil fuels because it is clean and renewable and contains a high energy density. Hydrogen storage in metals (such as $\mathrm{Mg}$ and $\mathrm{La}$ ) has numerous attractions such as high capacity, low cost, light weight and natural abundance. $\mathrm{Mg}$ and $\mathrm{Mg}$-based materials are known to be suitable for solid-state hydrogen storage. $\mathrm{Mg}$ is light, abundant and forms $\mathrm{MgH}_{2}$, which has a high storage capacity $(7.6 \mathrm{wt} \%)$ and an acceptable cost of production [1]. Yet, $\mathrm{MgH}_{2}$ is thermodynamically stable $\left(\Delta \mathrm{H}=-74.5 \mathrm{~kJ} \mathrm{~mol}^{-1}\right)$ and its hydrogen desorption is poor, below $350{ }^{\circ} \mathrm{C}$ [2]. The destabilization of $\mathrm{MgH}_{2}$ can be performed by decreasing the particle size of the material, preferably down to the nanoscale, and addition of catalysts [3-5]. Decreasing the particle size can result in more free surface and, therefore, better kinetics can result from short diffusion pathways along grain boundaries.

Improvement of the storage behavior of $\mathrm{MgH}_{2}$ has been investigated using several catalysts, including elemental [6-10], intermetallic [11-14], oxide [5, 15-18], halide [19-22], hydride [23-25] and other additives [26, 27]. Among the oxide catalysts, $\mathrm{TiO}_{2}$ is known to be remarkable. Many investigations have been performed on the catalytic effect of $\mathrm{TiO}_{2}$ on $\mathrm{MgH}_{2}$ [5, 16, 27-29]. Wang et al. [30] milled a mixture of $\mathrm{Mg}$ and $10 \mathrm{wt} \%$ of $\mathrm{TiO}_{2}$ for $6 \mathrm{~h}$ and claimed that $\mathrm{TiO}_{2}$ particles provided a diffusion way for $\mathrm{H}$ atoms which improved the diffusion rate, and, consequently, the desorption of hydrogen. Polanski et al. [16] ball-milled $\mathrm{MgH}_{2}$ with $\mathrm{Cr}_{2} \mathrm{O}_{3}, \mathrm{Fe}_{3} \mathrm{O}_{4}, \mathrm{Fe}_{2} \mathrm{O}_{3}$ and $\mathrm{TiO}_{2}$ for $20 \mathrm{~h}$. They reported that among all the oxide additives, $\mathrm{TiO}_{2}$ showed the best kinetics in desorption. Gattia et al. 
[31] ball milled $\mathrm{MgH}_{2}$ with $5 \mathrm{wt} \%$ of $\mathrm{TiO}_{2}$ and then added expanded natural graphite. They stated that the kinetics was improved and a good cyclability was also observed. Also, it has been proved that $\mathrm{TiO}_{2}$ has a better catalytic effect in the form of anatase compared to rutile [32]. The effect of elemental nickel on $\mathrm{MgH}_{2}$ [4, 7, 9, 33] and the hydrogen storage properties of $\mathrm{Mg}+\mathrm{NiO}$ and $\mathrm{MgH}_{2}+-$ $\mathrm{NiO}$ mixtures have also been studied [34, 35]; however, to the best of our knowledge, the catalytic effect of $\mathrm{NiO}+\mathrm{TiO}_{2}$ on $\mathrm{MgH}_{2}$ has not yet been investigated. It has been reported that the presence of two oxide catalysts can improve the hydrogen storage properties of $\mathrm{MgH}_{2}$ compared to one oxide catalyst [36]. In this study, we investigated the hydrogen desorption properties of $\mathrm{MgH}_{2}-\mathrm{TiO}_{2}-$ $\mathrm{NiO}$, as well as $\mathrm{MgH}_{2}-\mathrm{TiO}_{2}$ and $\mathrm{MgH}_{2}-\mathrm{NiO}$ nanocomposites. In this regard, the phase constituent of the powder mixture after ball milling, morphology, size and distribution of the particles, and the hydrogen storage properties of the samples were studied.

\section{The experiment}

\section{Material preparation}

$\mathrm{MgH}_{2}$ (Alfa Aesar, <140 $\mu \mathrm{m}$, purity: 98\%), $\mathrm{TiO}_{2}$ (Merck, $<0.2 \mu \mathrm{m}$, purity: 99.5\%) and $\mathrm{NiO}$ (Scharlau, Spain, $<20 \mu \mathrm{m}$, purity: $99.9 \%$ ) powders were used as raw materials. The powders were ball milled using high-energy planetary ball mill (Asia Sanat Rakhsh/2400) with a ball to powder ratio of 20:1 and a rotation speed of 250 RPM under a high-purity argon atmosphere for $15 \mathrm{~h}$. For the milling process, a hardened $\mathrm{Cr}$-steel vial accompanied by hardened bearing steel balls with 8-, 10- and 15-mm diameters were used. In all the samples, $5 \mathrm{wt} \%$ of catalyst was added to $\mathrm{MgH}_{2}$. About $1 \mathrm{wt} \%$ of stearic acid (Alfa Aesar, purity: $>99 \%$ ) was used as a process control agent (PCA).

\section{Material characterization}

Phase composition analysis was performed using a Philips $\mathrm{X}^{\prime}$ Pert Pro diffractometer with $\mathrm{Cu} \mathrm{k} \alpha(\lambda=0.1541874 \mathrm{~nm})$ radiation with a step size of $0.02^{\circ}$ and $X^{\prime}$ Pert High Score Plus v2.2b (PANalytical Company). The mean crystallite size and the lattice micro strain of the particles were measured using the Williamson-Hall method [37]:

$\beta_{\text {sample }} \cos \theta=K \lambda / \delta+2 \varepsilon \sin \theta$,

where $\beta_{\text {sample }}$ is the full width at half-maximum (FWHM) of the milled powder, $\theta$ the position of the peak maximum, $K$ the Scherrer constant (about 0.9), $\lambda$ the beam wavelength, $\delta$ the crystallite size, and $\varepsilon$ the lattice micro strain introduced by ball milling. For instrumental correction, the Gaussian relationship was used [38]:

$\beta_{\text {sample }}=\sqrt{\beta_{\text {experimental }}^{2}-\beta_{\text {instrumental }}^{2}}$

where $\beta_{\text {experimental }}$ is the measured FWHM of the annealed nickel powders.

Hydrogen desorption results were obtained and studied using a handmade Sievert apparatus. The activation of samples in the Sievert method was performed at $190{ }^{\circ} \mathrm{C}$ under 4-bar pressure of highly pure hydrogen gas (with the purity of $99.99 \mathrm{wt} \%$ ).

The field emission scanning electron microscope (FESEM) Sigma (Zeiss Company) and the scanning electron microscope MV 2300 (Tescan Company) were used to observe the morphology and particle size of the powders. Image analysis was performed using MIP4 Student (Nahamin Pardazan Asia Company).

\section{Results and discussion}

\section{Phase analysis}

Figure 1 shows the X-ray diffraction (XRD) patterns of the samples after $15 \mathrm{~h}$ of ball milling. It can be observed from XRD patterns of ball-milled $\mathrm{MgH}_{2}$ (BMM) that the peaks of $\beta-\mathrm{MgH}_{2}$, which is known as low-pressure $\mathrm{MgH}_{2}$, are broadened after milling. This indicates that the crystalline size has decreased and strain has been induced in the lattice. The diffraction pattern of the BMM sample shows one obvious $\mathrm{MgO}$ peak and one peak overlapping the $\mathrm{MgH}_{2}$ peaks, which is in agreement with other studies [39]. The presence of $\mathrm{MgO}$ in the ball-milled samples is probably due to the high activity of $\mathrm{Mg}$ from $2 \%$ impurity in $\mathrm{MgH}_{2}$. The peaks of metastable $\gamma-\mathrm{MgH}_{2}$, which are not sharp but have been confirmed before [40], can be observed in the diffraction pattern. The formation of $\gamma-\mathrm{MgH}_{2}$ was also reported for samples which had been milled for more than $10 \mathrm{~h}$ [41]. As shown in Table 1, the crystallite size has decreased and the lattice strain increased in the BMM sample compared to the unmilled $\mathrm{MgH}_{2}$, indicating that more free active surface is available for recombination of hydrogen molecules as well as smaller diffusion pathway for hydrogen atoms.

The diffraction pattern of the sample with $\mathrm{TiO}_{2}$ catalyst in the form of anatase (MT) shows the presence $\mathrm{TiO}_{2}, \mathrm{MgH}_{2}$ and $\mathrm{MgO}$. The addition of hard oxide particles to the nonductile $\mathrm{MgH}_{2}$ helped decrease the crystallite size and introduce more strain to the lattice [42]. During the process of ball milling, the continuous fracture and micro-welding goes on up to the steady state [43]. Thus, as shown in Table 1, the addition of hard particle can help break up 


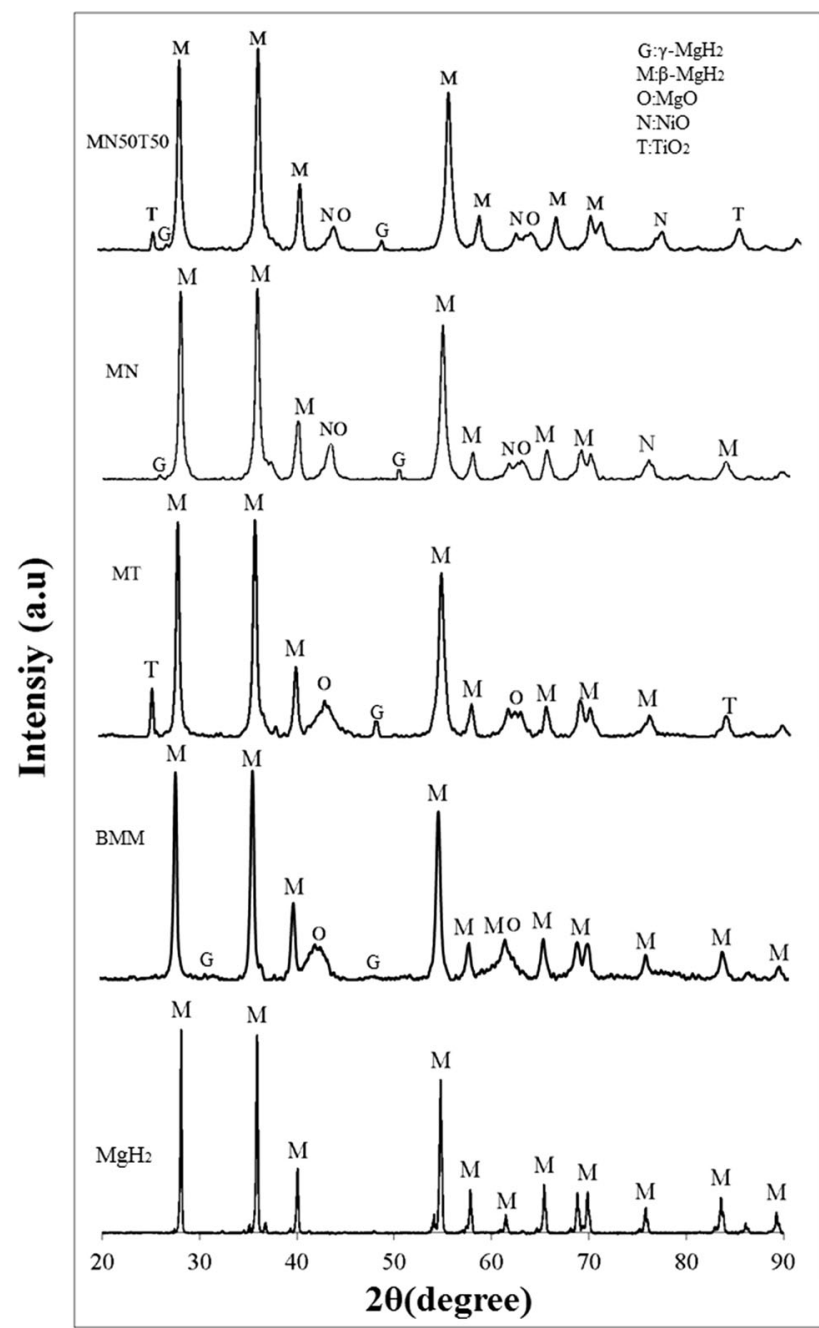

Fig. 1 XRD patterns of the different samples

Table 1 Mean crystallite size and lattice strain of the ball-milled powders

\begin{tabular}{lll}
\hline Sample name & Mean crystallite size $(\mathrm{nm})$ & Lattice strain $(\%)$ \\
\hline $\mathrm{MgH}_{2}$ & 45 & 0 \\
$\mathrm{BMM}$ & 38 & 0.11 \\
$\mathrm{MT}$ & 25 & 0.16 \\
$\mathrm{MN}$ & 28 & 0.14 \\
MN50T50 & 27 & 0.15 \\
\hline
\end{tabular}

$\mathrm{MgH}_{2}$ particles and result in decreasing of the crystallite size and increasing of lattice strain and active surface area [44]. The sample with $\mathrm{NiO}$ catalyst (MN) shows the presence of $\mathrm{NiO}$ and $\mathrm{MgH}_{2}$ and overlapped $\mathrm{MgO}$ peaks at $43^{\circ}$ and $62^{\circ}$. Due to the hard nature of the oxides, they can be used as a particle refinement agent; therefore, as shown in Table 1, this sample shows reduced crystallite size and increased lattice strain. All the raw materials were present in the XRD pattern of the sample with $5 \mathrm{wt} \%$ of catalyst containing a mixture of $50 \mathrm{wt} \%$ of $\mathrm{TiO}_{2}$ and $50 \mathrm{wt} \%$ of $\mathrm{NiO}$ (MN50T50). This sample contained two types of oxidic catalysts and, as a result, its crystallite size decreased compared to that of the BMM sample, and its lattice strain increased. No new binary or ternary components were formed in any of the catalyst-containing samples.

It is clear that the differences between the mean crystallite size and lattice strain of all three catalyzed samples are negligible. This could be due to the equality of the sample preparation process, ball mill time and ball to powder ratio for all the samples.

\section{Morphology of the powders}

Figure 2 shows the FESEM images of the (a) as-received $\mathrm{MgH}_{2}$, (b) BMM, (c) MN, (d) MT and (e) MN50T50 samples. The results of image analysis of different FESEM images of the samples are shown in Fig. 3. The particle size of the mixture has significantly reduced after $15 \mathrm{~h}$ of ball milling, as shown in Figs. $2 \mathrm{~b}$ and $3 \mathrm{a}$ for the BMM sample. It is obvious that mechanical milling is effective in decreasing the size of particles and providing more fresh active surface. It has been reported that the kinetics of $\mathrm{MgH}_{2}$ can be enhanced by decreasing the particle size, which can lead to a reduction in the hydrogen diffusion pathway [45]. It seems that the highest cumulative value for the distribution of particle size in all samples is between 80 and $250 \mathrm{~nm}$, and the cumulative value for larger particles is negligible. The inhomogeneous contact of the powders and steel balls during the ball-milling process could be the cause of this inhomogeneous particle size distribution [46]. It can be observed that the addition of catalyst to the $\mathrm{MgH}_{2}$ and $15 \mathrm{~h}$ of ball milling reduce the particle size, which can have the benefit of more free surface and probably result in increased hydrogen desorption [38]. As shown in Fig. 3, the emergence of smaller particles in the catalyzed sample can confirm that the presence of hard oxide particles in the non-ductile $\mathrm{MgH}_{2}$ can result in a smaller particle size and, consequently, a better hydrogen desorption behavior. The emergence of nano-sized particles in the sample shows that high-energy ball milling is an ideal method to decrease the particle size of the powder particles down to the nano-scale and, consequently, increase the surface area and potential sites of hydrogen desorption.

Figure 4 shows the results of EDS analysis for the MN50T50 sample. It can be seen that the distributions of $\mathrm{TiO}_{2}$ and $\mathrm{NiO}$ on the surface of $\mathrm{MgH}_{2}$ are uniform and approximately the same. 

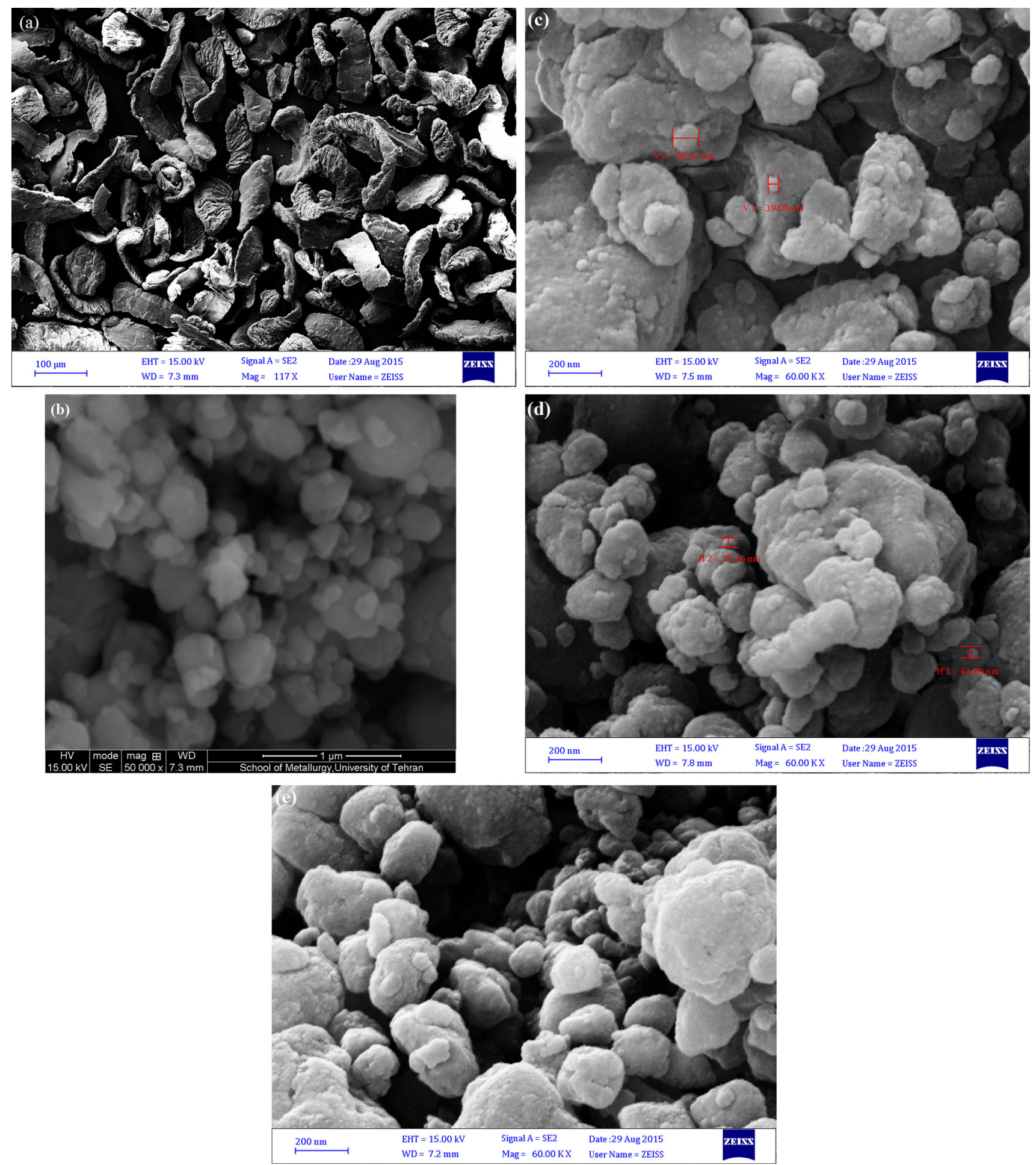

Fig. 2 FESEM images of a as-received $\mathrm{MgH}_{2}$, b BMM, c MN, d MT and e MN50T50 samples 

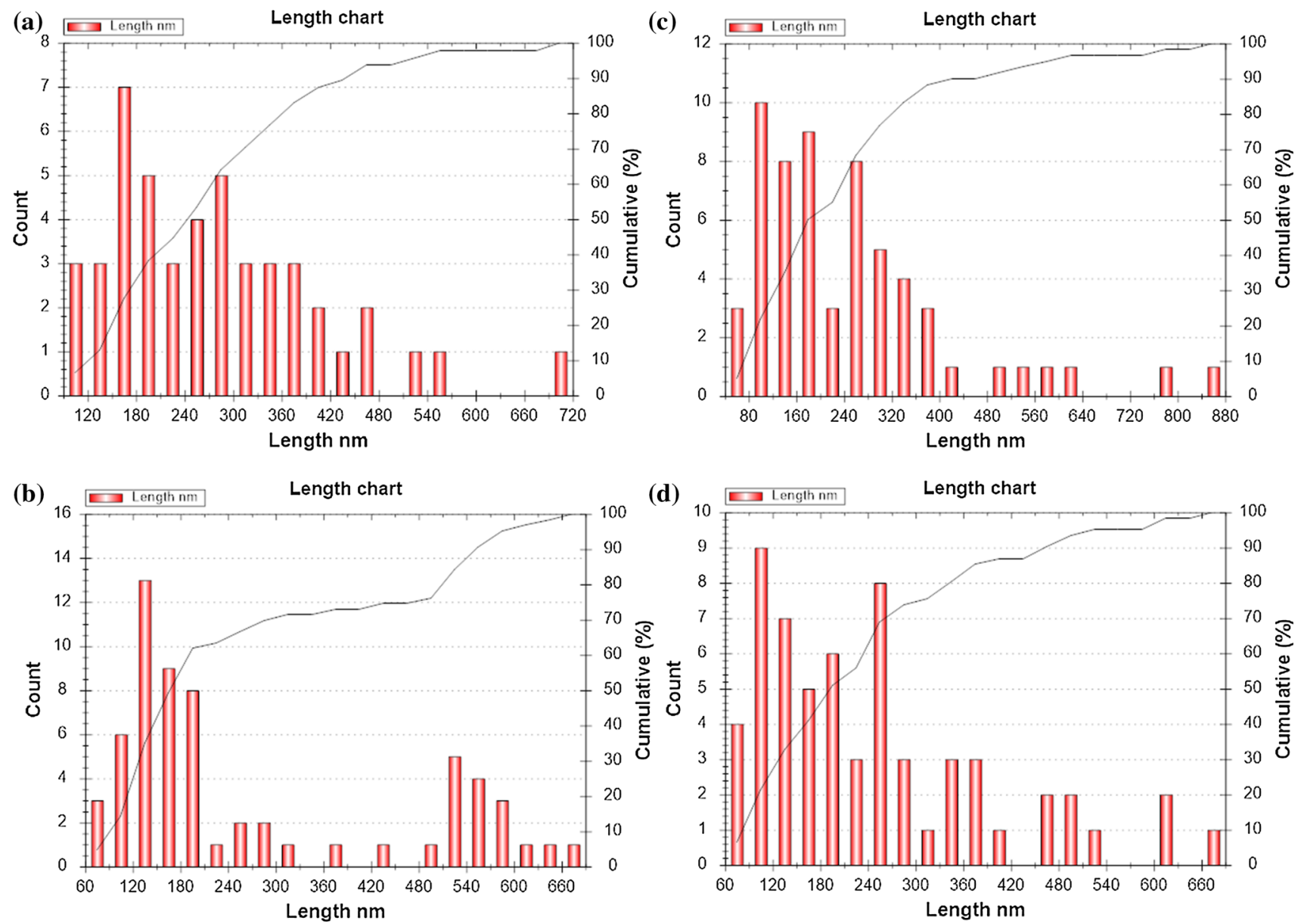

Fig. 3 Results of image analysis of the SEM images of a BMM, b MN, c MT and d MN50T50 samples

\section{Hydrogen desorption properties}

\section{$\mathrm{MgH}_{2}$ and $\mathrm{BMM}$ samples}

Figure 5 shows the hydrogen desorption results of the asreceived $\mathrm{MgH}_{2}, \mathrm{BMM}, \mathrm{MT}, \mathrm{MN}$ and MN50T50 samples, obtained from the Sievert apparatus at $350{ }^{\circ} \mathrm{C}$. The desorption rate of the samples in the first $200 \mathrm{~s}$ of the desorption process is shown in Fig. 6. Moreover, Fig. 7 demonstrates the onset time of desorption for various samples. It should be mentioned that the threshold of hydrogen desorption onset time has been considered to be after $0.5 \mathrm{wt} \%$ of hydrogen desorption. While $\mathrm{MgH}_{2}$ desorbed nothing after $2500 \mathrm{~s}$, the BMM sample desorbed $1.10 \mathrm{wt} \%$ of hydrogen starting after $642 \mathrm{~s}$ with a slow rate within the first 200 s, as shown in Figs. 6 and 7, which is in good agreement with previous studies [47, 48]. For example, Chitsazkhoyi et al. [47] claimed that after $30 \mathrm{~h}$ of ball milling, pure $\mathrm{MgH}_{2}$ released about 1 wt\% of hydrogen. In that research, all the samples which had been ball milled for less than $30 \mathrm{~h}$, released less than $1 \mathrm{wt} \%$ of hydrogen. It has been claimed that increasing the hydrogen desorption of ball-milled $\mathrm{MgH}_{2}$ could be due to the (1) refinement of the powder particles, (2) higher specific surface area which can lead to more active sites for gassolid reaction, (3) decreasing of the pathways for the diffusion of hydrogen through nanometric grains and (4) the lattice strain which was introduced to the system and can affect the diffusion and thus the decomposition rate [36]. In addition, the presence of metastable $\gamma-\mathrm{MgH}_{2}$ can affect the desorption process. Since the $\gamma-\mathrm{MgH}_{2}$ has a lower desorption enthalpy, its presence in the mixture can help the desorption kinetics [41]. It has been proposed that the rate-limiting step for hydrogen desorption is either the diffusion pathway of hydrogen through the grains to the surface or the recombination of hydrogen molecules on the surface of the particles [42]. In both theories, particle size decrease can enhance the desorption kinetics. Mechanical milling can reduce the diffusion pathways by decreasing the particle size, which can also increase the active surface area for the recombination of hydrogen molecules. 


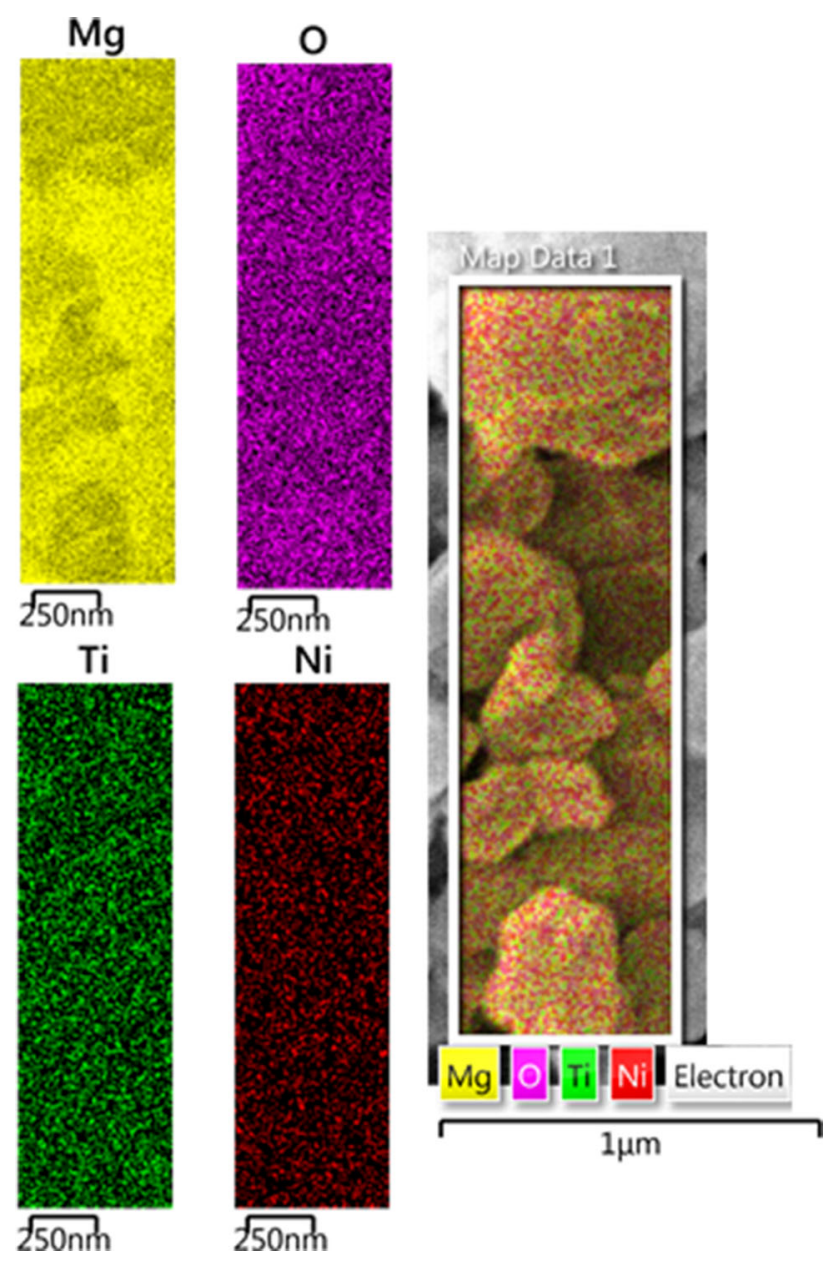

Fig. 4 EDS analysis of the MN50T50 sample
The effect of $\mathrm{NiO}$

According to previous studies, the addition of catalysts can enhance kinetics using the spillover mechanism by allowing electron transfer and hydrogen dissociation/recombination on the surface of the catalyst [49]. With the addition of $\mathrm{NiO}$, the desorption process starts after $119 \mathrm{~s}$, and the desorption rate is higher than that of the BMM and MN50T50 samples within the first 200 s. Desorption of hydrogen accedes to a steady state after about $900 \mathrm{~s}$ and no more hydrogen is desorbed. The mixture in the presence of $\mathrm{NiO}$ desorbs $2.94 \mathrm{wt} \%$ at $350{ }^{\circ} \mathrm{C}$. This result is in agreement with those of previous studies [34]. As it was discussed before, the decreasing of the onset time compared to the non-catalyzed $\mathrm{MgH}_{2}$ could be related to the presence of hard oxide particles which can lead to a smaller crystallite size and more lattice strain (Table 1), the spillover mechanism and the presence of $\gamma-\mathrm{MgH}_{2}$.

\section{The effect of $\mathrm{TiO}_{2}$}

The addition of $\mathrm{TiO}_{2}$ enhanced the desorption behavior of $\mathrm{MgH}_{2}$. The MT sample desorbed $1.97 \mathrm{wt} \%$. The desorption starts after $59 \mathrm{~s}$ at $350{ }^{\circ} \mathrm{C}$, which is the fastest of all samples, and continues with a moderate rate within the first $200 \mathrm{~s}$. Hydrogen desorption from the MT sample was in a steady state after about $1000 \mathrm{~s}$. The amount of hydrogen desorbed from the MT sample is in agreement with those reported in previous studies. For instance, Wang et al. [50] reported that the sample which had been milled with $\mathrm{TiO}_{2}$ for $10 \mathrm{~h}$

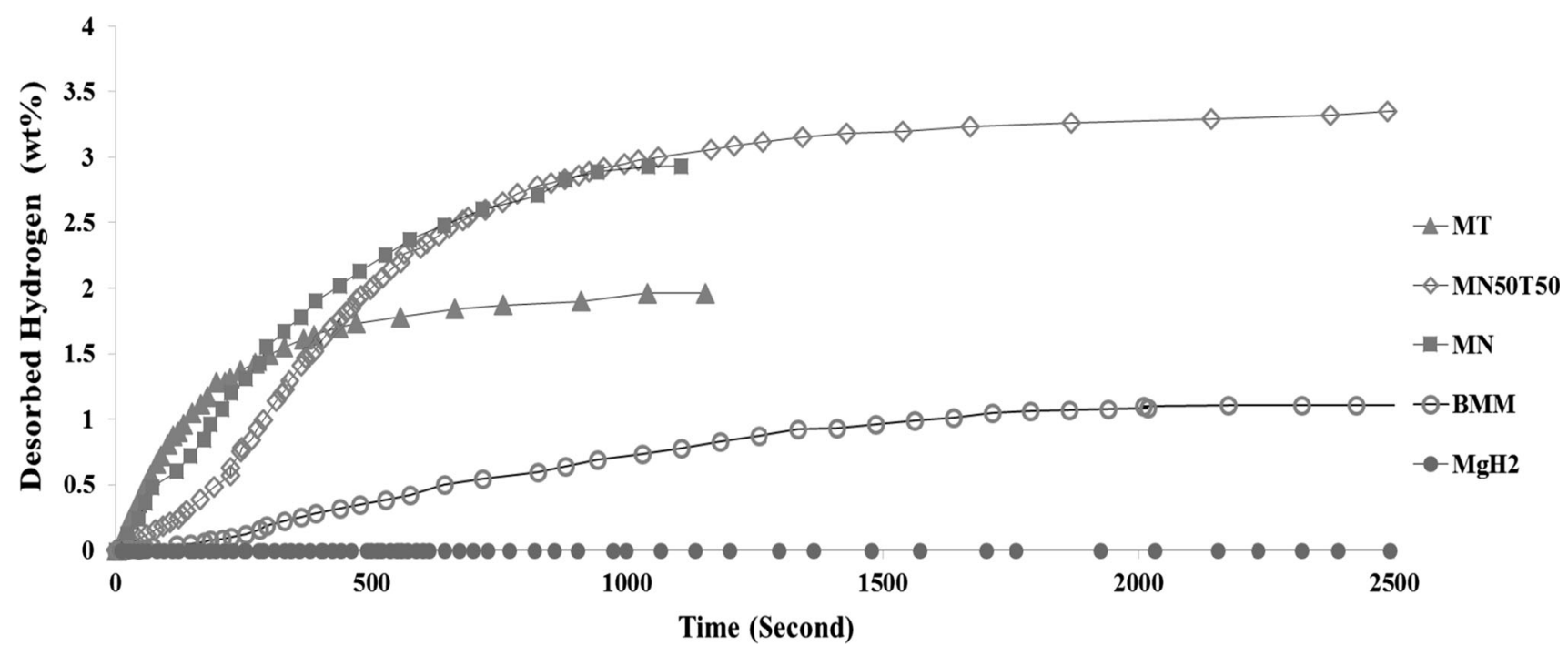

Fig. 5 Hydrogen desorption results of $\mathrm{MgH}_{2}, \mathrm{MT}, \mathrm{MN}$ and MN50T50 samples 


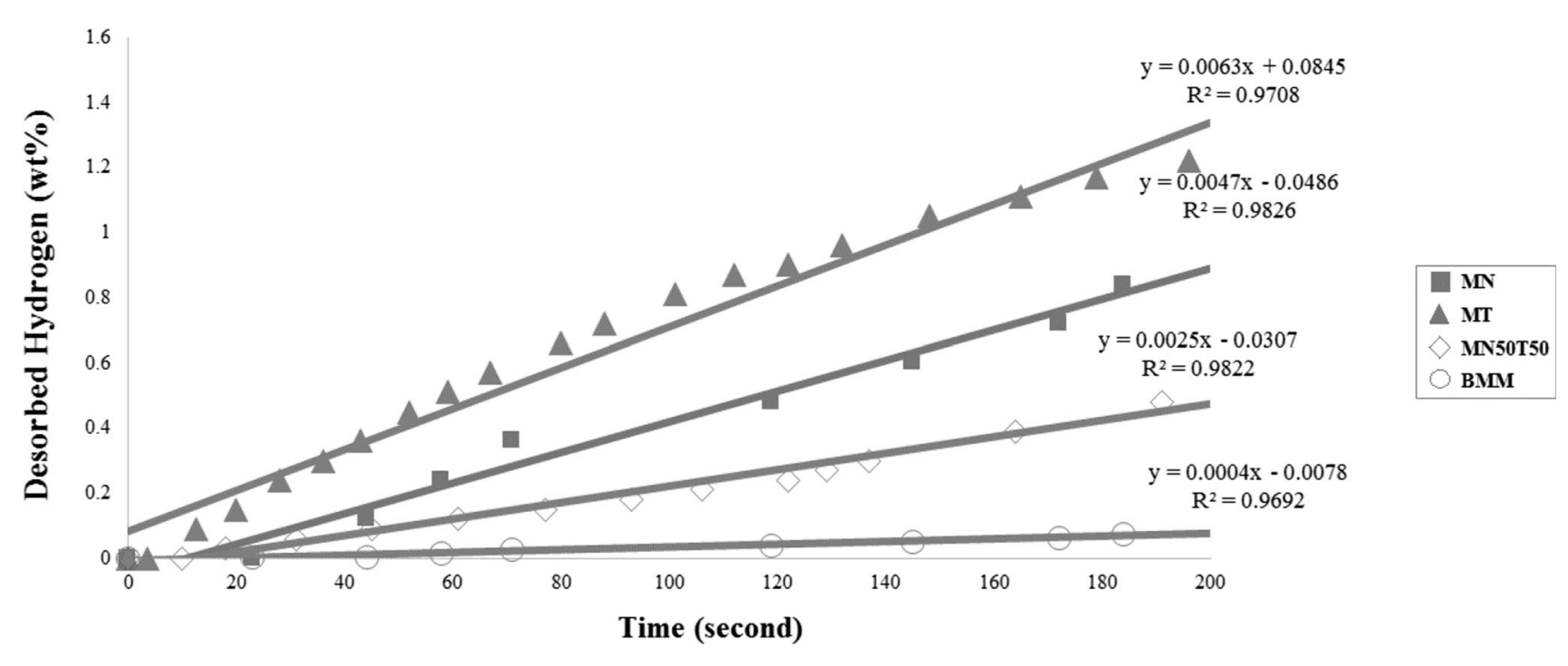

Fig. 6 Desorption results of the samples within the first $200 \mathrm{~s}$

Fig. 7 Onset time of hydrogen desorption of the samples

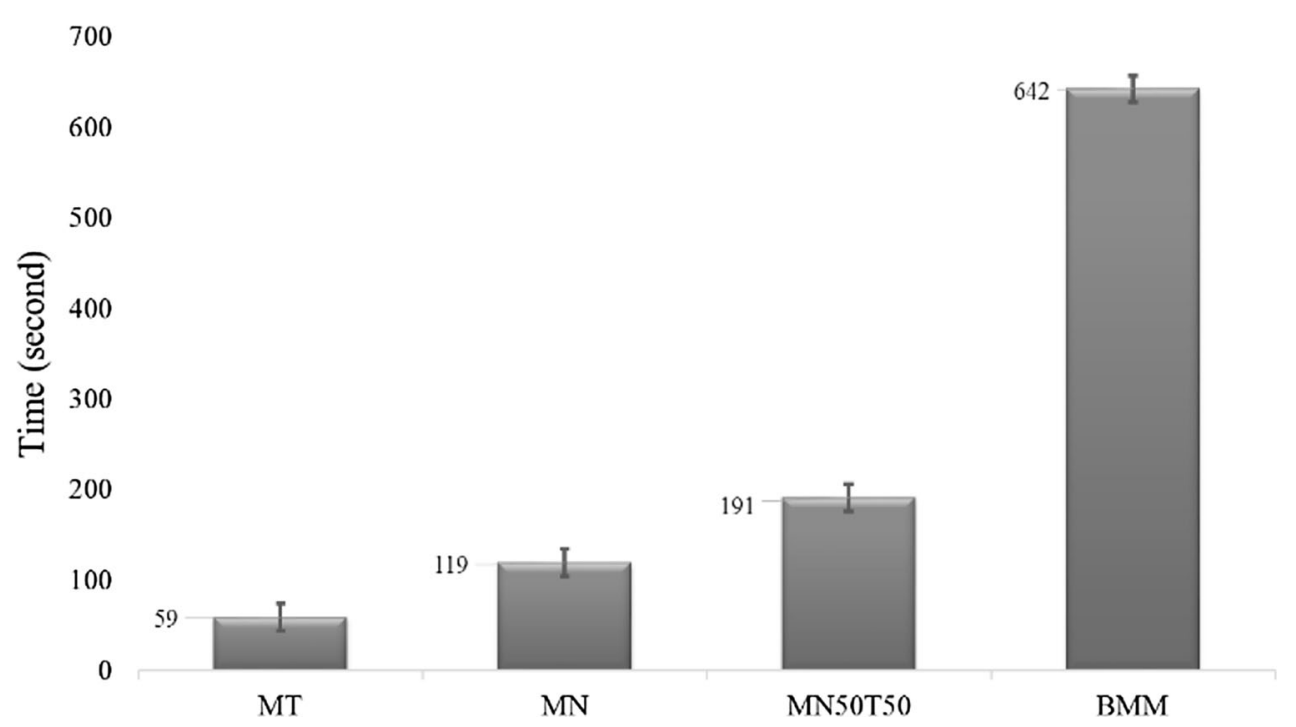

released $1 \mathrm{wt} \%$ of hydrogen. It was proved that the low hydrogen desorption capacity of $\mathrm{TiO}_{2}$-containing sample could be due to the formation of $\mathrm{TiH}_{1.971}$ during the desorption process [51]. In addition to the abovementioned reasons, it was claimed that $\mathrm{TiO}_{2}$ was reduced during the desorption process which resulted in active species responsible for the enhancement of hydrogen desorption [32].

\section{Simultaneous effects of $\mathrm{TiO}_{2}$ and $\mathrm{NiO}$}

The decomposition of MN50T50 led to the desorption of $3.35 \mathrm{wt} \%$ of hydrogen. This sample started hydrogen desorption after $191 \mathrm{~s}$ with a relatively low rate, but continued to desorb it up to $2500 \mathrm{~s}$. It can be concluded that the difference between hydrogen desorption of MN50T50 and that of the other two catalyzed samples is related to the chemical composition of the mixture, since (1) the procedure of sample preparing and desorption test was the same for all the samples, (2) the crystallite size and the lattice strain differences of the catalyzed samples were negligible, (3) the XRD for none of the samples showed the existence of new binary or ternary compounds and (4) the elemental distributions of the catalysts were homogeneous and the same. It seems that the simultaneous presence of both catalysts resulted in a synergic effect, leading to a higher desorbed hydrogen content.

\section{Conclusions}

The hydrogen desorption of $\mathrm{MgH}_{2}$ catalyzed with two different oxidic catalysts was investigated in the present study. It was proved that hydrogen desorption increased by mechanical milling and the addition of the catalysts, due to 
the decrease of the particle size and increase of the active sites for hydrogen desorption, as well as the effect of catalysts. Ball-milled $\mathrm{MgH}_{2}$ desorbed $1.1 \mathrm{wt} \%$ of hydrogen at $350{ }^{\circ} \mathrm{C}$, while the unmilled $\mathrm{MgH}_{2}$ desorbed nothing under the same condition. The addition of $5 \mathrm{wt} \%$ of $\mathrm{TiO}_{2}$ increased the hydrogen desorption of the mixture and resulted in a $1.97 \mathrm{wt} \%$ desorption of hydrogen at $350{ }^{\circ} \mathrm{C}$, which could be related to the catalytic effect of anatase as well as mechanical milling. In the presence of $\mathrm{NiO}, \mathrm{MgH}_{2}$ desorbed $2.94 \mathrm{wt} \%$ of hydrogen at $350{ }^{\circ} \mathrm{C}$. In the simultaneous presence of $\mathrm{NiO}$ and $\mathrm{TiO}_{2}$, the samples desorbed $3.35 \mathrm{wt} \%$ of hydrogen, which could be related to the synergic effect of $\mathrm{TiO}_{2}$ and $\mathrm{NiO}$ catalysts. There was no evidence of new binary or ternary compounds in the X-ray results of the catalyst-containing samples; thus, the differences in hydrogen desorption could not be related to the formation of new compounds. Moreover, with decrease in the particle and crystallite size, the lattice strain increased in all of the samples; but the differences were not big enough to cause a significant difference in the amount of desorbed hydrogen. Thus, it seems that these differences are the result of synergism of catalysts.

\section{Compliance with ethical standards}

Conflict of interest The authors declare that they have no conflict of interest.

Open Access This article is distributed under the terms of the Creative Commons Attribution 4.0 International License (http:// creativecommons.org/licenses/by/4.0/), which permits unrestricted use, distribution, and reproduction in any medium, provided you give appropriate credit to the original author(s) and the source, provide a link to the Creative Commons license, and indicate if changes were made.

\section{References}

1. Chen, B.-H., Chuang, Y.-S.: Improving the hydrogenation properties of $\mathrm{MgH}_{2}$ at room temperature by doping with nano-size $\mathrm{ZrO}_{2}$ catalyst. J. Alloy. Compd. 655, 21-27 (2016)

2. Maddalena, A., Petris, M., Palade, P., Sartori, S., Principi, G., Settimo, E., et al.: Study of Mg-based materials to be used in a functional solid state hydrogen reservoir for vehicular applications. Int. J. Hydrog. Energy 31, 2097-2103 (2006)

3. Nielsen, T.K., Manickam, K., Hirscher, M., Besenbacher, F., Jensen, T.R.: Confinement of $\mathrm{MgH}_{2}$ nanoclusters within nanoporous aerogel scaffold materials. ACS Nano 3, 3521-3528 (2009)

4. Liang, G., Huot, J., Boily, S., Van Neste, A., Schulz, R.: Catalytic effect of transition metals on hydrogen sorption in nanocrystalline ball milled $\mathrm{MgH}_{2}-\mathrm{Tm}(\mathrm{Tm}=\mathrm{Ti}, \mathrm{V}, \mathrm{Mn}, \mathrm{Fe}$ and $\mathrm{Ni})$ systems. J. Alloy. Compd. 292, 247-252 (1999)

5. Oelerich, W., Klassen, T., Bormann, R.: Metal oxides as catalysts for improved hydrogen sorption in nanocrystalline Mg-based materials. J. Alloy. Compd. 315, 237-242 (2001)

6. Varin, R., Li, S., Chiu, C., Guo, L., Morozova, O., Khomenko, T., et al.: Nanocrystalline and non-crystalline hydrides synthesized by controlled reactive mechanical alloying/milling of $\mathrm{Mg}$ and $\mathrm{Mg}-\mathrm{X}(\mathrm{X}=\mathrm{Fe} \mathrm{Co}, \mathrm{Mn}, \mathrm{B})$ systems. J. Alloy. Compd. 404, 494-498 (2005)

7. Bobet, J., Akiba, E., Nakamura, Y., Darriet, B.: Study of Mg-M $(\mathrm{M}=\mathrm{Co}, \mathrm{Ni}$ and $\mathrm{Fe}$ ) mixture elaborated by reactive mechanical alloying-Hydrogen sorption properties. Int. J. Hydrog. Energy 25, 987-996 (2000)

8. Denis, A., Sellier, E., Aymonier, C., Bobet, J.-L.: Hydrogen sorption properties of magnesium particles decorated with metallic nanoparticles as catalyst. J. Alloy. Compd. 476, 152-159 (2009)

9. Bobet, J.-L., Chevalier, B., Song, M.-Y., Darriet, B., Etourneau, $\mathrm{J}$. : Reactive mechanical grinding of magnesium in hydrogen and the effects of additives. Mater. Manuf. Process. 17, 351-361 (2002)

10. Jeon, K.-J., Theodore, A., Wu, C.-Y., Cai, M.: Hydrogen absorption/desorption kinetics of magnesium nano-nickel composites synthesized by dry particle coating technique. Int. J. Hydrog. Energy 32, 1860-1868 (2007)

11. Sabitu, S., Gallo, G., Goudy, A.: Effect of $\mathrm{TiH}_{2}$ and $\mathrm{Mg}_{2} \mathrm{Ni}$ additives on the hydrogen storage properties of magnesium hydride. J. Alloy. Compd. 499, 35-38 (2010)

12. Yu, X., Yang, Z., Liu, H., Grant, D., Walker, G.S.: The effect of a Ti-V-based BCC alloy as a catalyst on the hydrogen storage properties of $\mathrm{MgH}_{2}$. Int. J. Hydrog. Energy 35, 6338-6344 (2010)

13. Pighin, S., Capurso, G., Russo, S.L., Peretti, H.: Hydrogen sorption kinetics of magnesium hydride enhanced by the addition of $\mathrm{Zr}_{8} \mathrm{Ni}_{21}$ alloy. J. Alloy. Compd. 530, 111-115 (2012)

14. Laversenne, L., Andrieux, J., Plante, D., Lyard, L., Miraglia, S.: In operando study of $\mathrm{TiVCr}$ additive in $\mathrm{MgH}_{2}$ composites. Int. J. Hydrog. Energy 38, 11937-11945 (2013)

15. Song, M., Bobet, J.-L., Darriet, B.: Improvement in hydrogen sorption properties of $\mathrm{Mg}$ by reactive mechanical grinding with Cr $2 \mathrm{O} 3, \mathrm{Al} 2 \mathrm{O} 3$ and $\mathrm{CeO}$ 2. J. Alloy. Compd. 340, 256-262 (2002)

16. Polanski, M., Bystrzycki, J.: Comparative studies of the influence of different nano-sized metal oxides on the hydrogen sorption properties of magnesium hydride. J. Alloy. Compd. 486, 697-701 (2009)

17. Borgschulte, A., Bösenberg, U., Barkhordarian, G., Dornheim, M., Bormann, R.: Enhanced hydrogen sorption kinetics of magnesium by destabilized $\mathrm{MgH}_{2}-\delta$. Catal. Today 120, 262-269 (2007)

18. Milošević, S., Rašković-Lovre, Ž., Kurko, S., Vujasin, R., Cvjetićanin, N., Matović, L., et al.: Influence of VO 2 nanostructured ceramics on hydrogen desorption properties from magnesium hydride. Ceram. Int. 39, 51-56 (2013)

19. Ivanov, E., Konstanchuk, I., Bokhonov, B., Boldyrev, V.: Hydrogen interaction with mechanically alloyed magnesium-salt composite materials. J. Alloy. Compd. 359, 320-325 (2003)

20. Jin, S.-A., Shim, J.-H., Cho, Y.W., Yi, K.-W.: Dehydrogenation and hydrogenation characteristics of $\mathrm{MgH}_{2}$ with transition metal fluorides. J. Power Sourc. 172, 859-862 (2007)

21. Deledda, S., Borissova, A., Poinsignon, C., Botta, W., Dornheim, M., Klassen, T.: H-sorption in $\mathrm{MgH}_{2}$ nanocomposites containing Fe or Ni with fluorine. J. Alloy. Compd. 404, 409-412 (2005)

22. Malka, I., Bystrzycki, J., Płociński, T., Czujko, T.: Microstructure and hydrogen storage capacity of magnesium hydride with zirconium and niobium fluoride additives after cyclic loading. J. Alloy. Compd. 509, S616-S620 (2011)

23. Lu, J., Choi, Y.J., Fang, Z.Z., Sohn, H.Y., Rönnebro, E.: Hydrogen storage properties of nanosized $\mathrm{MgH}_{2}-0.1 \mathrm{TiH}_{2}$ prepared by ultrahigh-energy - high-pressure milling. J. Am. Chem. Soc. 131, 15843-15852 (2009)

24. Yavari, A., De Castro, J., Vaughan, G., Heunen, G.: Structural evolution and metastable phase detection in $\mathrm{MgH}_{2}-5 \% \mathrm{NbH}$ 
nanocomposite during in situ H-desorption in a synchrotron beam. J. Alloy. Compd. 353, 246-251 (2003)

25. Czujko, T., Varin, R., Wronski, Z., Zaranski, Z., Durejko, T.: Synthesis and hydrogen desorption properties of nanocomposite magnesium hydride with sodium borohydride $\left(\mathrm{MgH}_{2}+\mathrm{NaBH}_{4}\right)$. J. Alloy. Compd. 427, 291-299 (2007)

26. Ranjbar, A., Guo, Z., Yu, X., Attard, D., Calka, A., Liu, H.: Effects of $\mathrm{SiC}$ nanoparticles with and without $\mathrm{Ni}$ on the hydrogen storage properties of $\mathrm{MgH}_{2}$. Int. J. Hydrog. Energy 34, 7263-7268 (2009)

27. Pitt, M.P., Paskevicius, M., Webb, C., Sheppard, D., Buckley, C., Gray, E.M.: The synthesis of nanoscopic Ti based alloys and their effects on the $\mathrm{MgH}_{2}$ system compared with the $\mathrm{MgH}_{2}+0.01$ $\mathrm{Nb}_{2} \mathrm{O}_{5}$ benchmark. Int. J. Hydrog. Energy 37, 4227-4237 (2012)

28. Wang, P., Wang, A., Zhang, H., Ding, B., Hu, Z.: Hydrogenation characteristics of $\mathrm{Mg}-\mathrm{TiO}_{2}$ (rutile) composite. J. Alloy. Compd. 313, 218-223 (2000)

29. Jung, K.S., Kim, D.H., Lee, E.Y., Lee, K.S.: Hydrogen sorption of magnesium hydride doped with nano-sized TiO 2. Catal. Today 120, 270-275 (2007)

30. Wang, P., Zhang, H., Ding, B., Hu, Z.: Direct hydrogenation of $\mathrm{Mg}$ and decomposition behavior of the hydride formed. J. Alloy. Compd. 313, 209-213 (2000)

31. Gattia, D.M., Di Girolamo, G., Montone, A.: Microstructure and kinetics evolution in $\mathrm{MgH}_{2}-\mathrm{TiO}_{2}$ pellets after hydrogen cycling. J. Alloy. Compd. 615, S689-S692 (2014)

32. Croston, D.L.: The Effect of Metal Oxide Additives on the Hydrogen Sorption Behaviour of Magnesium Hydride. Doctoral dissertation, University of Nottingham (2007)

33. Hanada, N., Ichikawa, T., Fujii, H.: Catalytic effect of nanoparticle 3d-transition metals on hydrogen storage properties in magnesium hydride $\mathrm{MgH}_{2}$ prepared by mechanical milling. J. Phys. Chem. B 109, 7188-7194 (2005)

34. Khrussanova, M., Terzieva, M., Peshev, P., Konstanchuk, I., Ivanov, E.: Hydriding of mechanically alloyed mixtures of magnesium with $\mathrm{MnO}_{2}, \mathrm{Fe}_{2} \mathrm{O}_{3}$ and $\mathrm{NiO}$. Mater. Res. Bull. 26, 561-567 (1991)

35. Cabo, M., Garroni, S., Pellicer, E., Milanese, C., Girella, A., Marini, A., et al.: Hydrogen sorption performance of $\mathrm{MgH}_{2}$ doped with mesoporous nickel-and cobalt-based oxides. Int. J. Hydrog. Energy 36, 5400-5410 (2011)

36. Simchi, H., Kaflou, A., Simchi, A.: Synergetic effect of Ni and $\mathrm{Nb}_{2} \mathrm{O}_{5}$ on dehydrogenation properties of nanostructured $\mathrm{MgH}_{2}$ synthesized by high-energy mechanical alloying. Int. J. Hydrog. Energy 34, 7724-7730 (2009)

37. Williamson, G., Hall, W.: X-ray line broadening from filed aluminium and wolfram. Acta Metall. 1, 22-31 (1953)

38. Hosseini-Gourajoubi, F., Pourabdoli, M., Uner, D., Raygan, S.: Effect of process control agents on synthesizing nano-structured $2 \mathrm{Mg}-9 \mathrm{Ni}-\mathrm{Y}$ catalyst by mechanical milling and its catalytic effect on desorption capacity of $\mathrm{MgH}_{2}$. Adv. Powder Technol. 26, 448-453 (2015)

39. Shahi, R.R., Bhatnagar, A., Pandey, S.K., Dixit, V., Srivastava, O.: Effects of Ti-based catalysts and synergistic effect of SWCNTs- $\mathrm{TiF}_{3}$ on hydrogen uptake and release from $\mathrm{MgH}_{2}$. Int. J. Hydrog. Energy 39, 14255-14261 (2014)

40. Huot, J., Liang, G., Boily, S., Van Neste, A., Schulz, R.: Structural study and hydrogen sorption kinetics of ball-milled magnesium hydride. J. Alloy. Compd. 293, 495-500 (1999)

41. Varin, R., Czujko, T., Wronski, Z.: Particle size, grain size and $\gamma$ $\mathrm{MgH}_{2}$ effects on the desorption properties of nanocrystalline commercial magnesium hydride processed by controlled mechanical milling. Nanotechnology 17, 3856 (2006)

42. Walker, G.: Solid-State Hydrogen Storage: Materials And Chemistry. Elsevier, Woodhead Publishing Limited, Cambridge, England (2008)

43. Reule, H., Hirscher, M., Weißhardt, A., Kronmüller, H.: Hydrogen desorption properties of mechanically alloyed $\mathrm{MgH}_{2}$ composite materials. J. Alloy. Compd. 305, 246-252 (2000)

44. Ranjbar, A.: Effect of catalysts on hydrogen storage properties of $\mathrm{MgH}_{2}$. Doctoral dissertation, Faculty of Engineering, University of Wollongong (2010)

45. Au, Y.S., Obbink, M.K., Srinivasan, S., Magusin, P.C., De Jong, K.P., De Jongh, P.E.: The size dependence of hydrogen mobility and sorption kinetics for carbon-supported $\mathrm{MgH} 2$ particles. Adv. Funct. Mater. 24, 3604-3611 (2014)

46. Liu, G., Wang, K., Li, J., Wang, Y., Yuan, H.: Enhancement of hydrogen desorption in magnesium hydride catalyzed by graphene nanosheets supported $\mathrm{Ni}-\mathrm{CeO}$ x hybrid nanocatalyst. Int. J. Hydrog. Energy 41(25), 10786-10794 (2016)

47. ChitsazKhoyi, L., Raygan, S., Pourabdoli, M.: Effect of synthesized $\mathrm{MgNi}_{4} \mathrm{Y}$ catalyst on hydrogen desorption properties of milled $\mathrm{MgH}_{2}$. Metall. Mater. Trans. E 2, 27-32 (2015)

48. Pourabdoli, M., Raygan, S., Abdizadeh, H., Uner, D.: A comparative study for synthesis methods of nano-structured $(9 \mathrm{Ni}-$ $2 \mathrm{Mg}-\mathrm{Y}$ ) alloy catalysts and effect of the produced alloy on hydrogen desorption properties of $\mathrm{MgH}_{2}$. Int. J. Hydrog. Energy 38, 16090-16097 (2013)

49. Mitchell, P.C., Ramirez-Cuesta, A.J., Parker, S.F., Tomkinson, J., Thompsett, D.: Hydrogen spillover on carbon-supported metal catalysts studied by inelastic neutron scattering. Surface vibrational states and hydrogen riding modes. J. Phys. Chem. B 107, 6838-6845 (2003)

50. Wang, Y., Wu, S.W., Yu, H., Gong, N.N., Cao, Z.Q., Zhang, K.: Hydrogen desorption/absorption kinetics of $\mathrm{MgH}_{2}$ catalyzed with $\mathrm{TiO}_{2}$. Adv. Mater. Res. 986, 88-91 (2014)

51. Wang, Y., Zhang, Q., Wang, Y., Jiao, L., Yuan, H.: Catalytic effects of different Ti-based materials on dehydrogenation performances of $\mathrm{MgH}_{2}$. J. Alloy. Compd. 645, S509-S512 (2015) 